\title{
An Examination of Geologic Carbon Sequestration Policies in the Context of Leakage Potential
}

\author{
Jeffrey M. Bielicki ${ }^{\text {a, b }}$, Catherine A. Peters ${ }^{c}$, Jeffrey P. Fitts ${ }^{c}$, and Elizabeth J. Wilson ${ }^{d^{*}}$ \\ ${ }^{a}$ Department of Civil, Environmental, and Geodetic Engineering, The Ohio State University, \\ Columbus, OH 43201 \\ ${ }^{\mathrm{b}}$ The John Glenn School of Public Affairs, The Ohio State University, Columbus, OH 43201 \\ ${ }^{\mathrm{c}}$ Department of Civil and Environmental Engineering, Princeton University, Princeton, NJ 08544 \\ ${ }^{\mathrm{d}}$ Center for Science, Technology, and Public Policy, Hubert H. Humphrey School of Public \\ Affairs, University of Minnesota, Minneapolis, MN 55455 \\ *corresponding author: ewilson@umn.edu
}

\section{Abstract}

Carbon dioxide $\left(\mathrm{CO}_{2}\right)$ injected into geologic reservoirs for long-term sequestration, or the brine it displaces, may leak through natural or manmade pathways. Using a leakage estimation model, we simulated fluid leakage from a storage reservoir and its migration into overlying formations. The results are discussed in the context of policies that seek to assure long-term sequestration and protect groundwater. This work is based on a case study of $\mathrm{CO}_{2}$ injection into the Mt. Simon sandstone in the Michigan sedimentary basin, for which we constructed a simplified hydrologic representation of the geologic formations. The simulation results show that (1) $\mathrm{CO}_{2}$ leakage can reach an aquifer containing potable water, but numerous intervening stratigraphic traps limit the rate to be orders of magnitude less than the rate of leakage from the storage reservoir; (2) U.S. Department of Energy guidelines for storage permanence allow for more leakage from larger injection projects than for smaller ones; (3) well leakage permeability is the most important variable in determining leakage processes and substantial leakage requires that numerous wells leaking with the anomalously high permeability of $10^{-10} \mathrm{~m}^{2}$; and (4) leakage can reduce the U.S. Environmental Protection Agency's Area of Review.

Keywords:Carbon sequestration; geologic storage; leakage; CCS; CCUS policy; Area of Review; caprock

\section{Introduction}

Meeting goals for limiting future climate change entails the deployment of a broad portfolio of technologies that reduce the carbon dioxide $\left(\mathrm{CO}_{2}\right)$ emissions intensity of the energy used to power economies (GEA, 2012). Analyses often favor expanded deployment of renewable energy technologies combined with $\mathrm{CO}_{2}$ capture and storage (CCS) (GEA, 2012; Pacala and Socolow, 2004). CCS is a process whereby $\mathrm{CO}_{2}$ is captured from large stationary point sources (e.g., coal- 
fired power plants, ethanol refineries, cement manufacturers), compressed, and transported by pipeline to locations where that $\mathrm{CO}_{2}$ is injected deep into the subsurface for isolation from the atmosphere (IPCC, 2005). These subsurface storage options include depleted oil and gas reservoirs, unmineable coal seams, and deep saline aquifers (NETL, 2012); basalt formations may also offer storage potential (Matter et al., 2007). In the United States and Canada, the lowerbound estimate for $\mathrm{CO}_{2}$ storage capacity is $2,102 \mathrm{GtCO}_{2}$ in saline formations, compared to 226 $\mathrm{GtCO}_{2}$ in oil and gas reservoirs, and $56 \mathrm{GtCO}_{2}$ in unmineable coal seams (NETL, 2012). In some formations, injecting $\mathrm{CO}_{2}$ can create value by enhancing oil recovery (NETL, 2010), producing methane from gas reservoirs and coalbeds (Mazzotti et al., 2009), or generating electricity using geothermal resources (Buscheck et al., 2013, 2012; Randolph and Saar, 2011). As a consequence of the possibility to couple geologic $\mathrm{CO}_{2}$ injection with the production of a marketable commodity, CCS has been re-branded CCUS, where "U" refers to the "Utilization" of $\mathrm{CO}_{2}$. Future deployment of CCS or CCUS to make a substantial contribution to mitigating climate change will necessarily involve deep saline aquifers within sedimentary basins because they offer an enormous potential onshore storage capacity.

The viability of CCS as an effective climate mitigation technology depends on its reliability in terms of secure, long-term containment of $\mathrm{CO}_{2}$. Under the high-pressure conditions in the deep subsurface, $\mathrm{CO}_{2}$ will be a supercritical fluid — dense like a liquid but buoyant relative to the resident brine. Also, pressure increases in storage reservoirs will occur because $\mathrm{CO}_{2}$ will be injected into formations that already contain fluids (Birkholzer et al., 2009; Strandli and Benson, 2013), and this increase in pore pressure may mobilize the resident brine. Therefore, containment of the $\mathrm{CO}_{2}$ within a particular stratigraphic formation relies upon the integrity of an impervious caprock overlying the permeable and porous storage reservoir. Leakage from storage reservoirs is possible if $\mathrm{CO}_{2}$ or displaced brine encounters locations where caprock integrity is compromised. These potential leakage pathways include geologic faults and transmissive fracture systems (Jordan et al., 2011; Rutqvist, 2012; Zeidouni, 2012), poorly or improperly plugged wells, poorly-cemented existing wells and wellbores (e.g., Birkholzer et al., 2011; Tao et al., 2012; Watson and Bachu, 2007), altered well cement (e.g., Carey, 2013; Kutchko et al., 2007), the boundary between this cement and the well casing or host rock (e.g., Carey et al., 2010; Newell and Carey, 2013), or geochemically-altered fractures (e.g., Deng et al., 2013; Ellis et al., 2013, 2011; Fitts and Peters, 2013). Leakage may incur costs to a variety of stakeholders (Bielicki et al., 2014; Pollak et al., 2013), but moderate amounts of leakage may be tolerated from the perspective of climate mitigation (Hepple and Benson, 2004; van der Zwaan and Smekens, 2009) and cost effectiveness (Ha-Duong and Keith, 2003; van der Zwaan and Gerlagh, 2009). Leakage through leakage pathways could also relieve some pressure (Cihan et al., 2013) and thus reduce a driving force for upward migration of non-native fluids and the potential for inducing seismicity. Helpful pressure relief could also be provided by distant out-of zone brine migration or by diffuse flow of brine though the confining layer, but the loss of $\mathrm{CO}_{2}$ may limit the success of the project in part as a result of oversight and regulation by relevant agencies.

Oversight that allows some leakage can have benefits over those that prohibit leakage. For example, some degree of leakage can have performance benefits by reducing pressure, and operators can continue to accrue knowledge of how the reservoir behaviors despite, and because of, this leakage. The opaque and heterogeneous nature of the subsurface means that operators, regulators, the public, and other stakeholders can have at best probabilistic expectations of the security of a given geologic $\mathrm{CO}_{2}$ storage project. Agencies in the United States and elsewhere are seeking to limit leakage of injected and mobilized fluids, and some of their guidance and 
oversight incorporates the potential for some leakage, despite their different perspectives. For example, the European Union Directive on the Geological Storage of Carbon Dioxide does not allow permits for reservoirs that have a significant risk of leakage (European Union, 2009). In the United States, the Department of Energy (U.S. DOE) focuses on storage performance and has set a climate mitigation goal for $\mathrm{CO}_{2}$ storage of $99 \%$ storage permanence. That is, leaked $\mathrm{CO}_{2}$ would be limited to at most $1 \%$ of the amount of $\mathrm{CO}_{2}$ injected into a reservoir. The United States Environmental Protection Agency (U.S. EPA) focuses on environmental and human health and is charged with protecting potable groundwater resources under the Safe Drinking Water Act (SDWA). In the United States, an underground source of drinking water (USDW) is defined as an aquifer with less than 10,000 ppm total dissolved solids (TDS). For $\mathrm{CO}_{2}$ or brine to contaminate a USDW, these fluids must encounter vertical leakage pathways and flow, due to natural buoyancy or a pressure drive, through numerous intervening sedimentary units before reaching a USDW aquifer. Subsequent deterioration of water quality may result from the brine salinity or from the direct or indirect mobilization or release of toxic metals, trace elements, and normally occurring radioactive materials (NORMs) (Atchley et al., 2013; Humez et al., 2011; Keating et al., 2013, 2010; Lemieux, 2011; Lions et al., 2014; Little and Jackson, 2010; Yang et al., 2014a, 2014b). The U.S. EPA Underground Injection Control (UIC) program Class VI rule includes Above Zone Monitoring Intervals (AZMI), where the formations above the intended storage reservoir are monitored for leakage. If leakage is detected, leakage pathways could be repaired to reduce or stop leakage. If an impact of leakage is detected in a USDW, the injection site will violate the SDWA and be out of compliance with the UIC Class VI regulations that govern $\mathrm{CO}_{2}$ injection for storage.

The Class VI Rule (U.S. Federal Register, 2010), requires that an Area of Review (AoR) be delineated as "the region surrounding the proposed well where USDWs may be endangered by the injection activity [40 CFR 146.84]" (U.S. EPA, 2013). The AoR is thus the geographic area within which leakage could reach a USDW aquifer, and has been defined as either the area where the brine pressure is sufficiently elevated to drive fluid upward and into a shallow USDW aquifer, or the areal extent of the $\mathrm{CO}_{2}$ plume, and is delineated by whichever is larger (U.S. Federal Register, 2010). In contrast to the Class I rules for hazardous waste injection and the Class II rules for injecting waste from oil and gas production, which stipulate that assessments of the potential for leakage must be made at specific radial distances from the injection well (at least Class I $=3.2 \mathrm{~km}$, Class II $=0.8 \mathrm{~km}$ ), the Class VI rule requires a site-specific assessment. This rule requires that injection operators establish the AoR based on approved modeling of fluid flows [40 CFR 146.84(a)] (which have provided good fits of the extent of the $\mathrm{CO}_{2}$ plume in demonstration injections (Hovorka et al., 2006)), identify and characterize potential leakage pathways within the AoR [40 CFR 146.84(c)], conduct appropriate corrective action on artificial penetrations within the AoR through which leakage might reach a USDW [40 CFR 146.84(d)], and reassess this AoR and the penetrations over time [40 CFR 146.84(d, e)], (U.S. EPA, 2013). The AoR can cover a large area within the basin (Birkholzer and Zhou, 2009), and some have called for a tiered definition of the AoR based on the potential leakage of $\mathrm{CO}_{2}$ or of brine (Birkholzer et al., 2014).

Our previous work has examined how the regulatory discretion regarding this corrective action may influence the costs of leakage (Bielicki et al., 2014). Here we used very large injection rates in a consistent manner to examine the geophysical controls on leakage and the implications for policies governing geologic $\mathrm{CO}_{2}$ storage in the United States, with specific attention to the U.S. DOE storage permanence goal and the U.S. EPA Class VI rule. The U.S. 
DOE goal allows for some leakage, and we investigated scenarios of $\mathrm{CO}_{2}$ leakage that exceed the goal and if the approach of a constant rate may have unintended consequences of allowing more $\mathrm{CO}_{2}$ to leak from operations with higher injection rates. The U.S. EPA Class VI rule is examined in regard to the effect on the AoR as well as the potential of leakage to reach a USDW. Finally, we discuss the extent to which the U.S. DOE goal and the U.S. EPA rule are self consistent or at odds with each other by examining the extent to which allowed leaked $\mathrm{CO}_{2}$ from the storage reservoir leads to disallowed contamination of potable groundwater aquifers. The layered structure of sedimentary basins means that leaked $\mathrm{CO}_{2}$ disperses horizontally as well as vertically through the stratigraphic sequence and does not necessarily end up contaminating a USDW.

The total amount of leakage and the extent to which fluids migrate horizontally (defining the AoR) and vertically (defining the threat to a USDW) depend on numerous interacting parameters, including geophysical characteristics (e.g., leakage pathway permeability, unit permeability, unit porosity), siting choices (e.g., proximity to leakage pathways, depth and thickness of $\mathrm{CO}_{2}$ storage reservoir), and operational decisions (e.g., injection rate). In this work, we simulated leakage from a storage formation into overlying aquifers by running a semianalytical leakage model. Our case study is a hypothetical geologic $\mathrm{CO}_{2}$ storage project in a realistic target reservoir in the Michigan sedimentary basin, with very large injection rates to encourage substantial leakage rates. We constructed a three-dimensional model of the hydrostratigraphic units of the Michigan sedimentary basin based largely on the characterization by the United States Geologic Survey (USGS) (Lampe, 2009), and focused specifically on the aquifers in western Michigan. We examined three main sources of uncertainty and variability: the (1) porosity and (2) permeability of the $\mathrm{CO}_{2}$ storage reservoir, and (3) the permeabilities of existing wells as potential leakage pathways, or "leakage permeability". The contrast between formation permeability and leakage permeability influences the degree to which leaking fluids will continue to flow vertically or will spread horizontally. Porosity influences the amount of $\mathrm{CO}_{2}$ or displaced brine that can accumulate within the host rock. We examined these effects through a combination of parameter sensitivity analysis and probabilistic modeling.

\section{Methods}

\section{Injection and Leakage Modeling}

We applied a semi-analytical leakage estimation model that is a multi-phase flow simulator that describes $\mathrm{CO}_{2}$ plume evolution in horizontal aquifers, upconing around leakage points, and vertical flow through wells (Celia et al., 2011; Dobossy et al., 2011; Nordbotten et al., 2009). This model is designed for multi-layer systems so that the sequential transport of leaked fluids can be tracked through a vertical stack of sedimentary formations. Key to this model are process simplifications that allow the $\mathrm{CO}_{2}$ plume to be modeled at "vertical equilibrium" due to strong buoyancy segregation and that allow the plume to have a sharp interface by neglecting the capillary transition zone. These simplifications result in analytical solutions in the spatial dimension, leaving only the temporal dimension to be modeled numerically (hence the "semianalytical" descriptor). Unlike conventional numerical subsurface flow simulators, the semianalytical nature of this model makes it computationally tractable and amenable to probabilistic analyses (Celia et al., 2011; Nogues et al., 2012). Important system assumptions are that the hydrostratigraphic units are compiled into a sequence of alternating permeable units (aquifers) and impermeable caprocks (aquitards), each of which are horizontal and homogeneous, such that porosity and permeability parameters for each unit are spatially uniform. 
Previous investigations have used this model and similar probabilistic approaches to investigate the effects of residual brine saturation, injection depth, and leakage pathway permeabilities, on the magnitude of leakage for a case study in Alberta, Canada (Celia et al., 2011; Nogues et al., 2012). Leakage pathway permeabilities were found to be the most uncertain component of these simulations. Nogues et al. (2012) assigned well leakage permeabilities using a bimodal distribution, where one mode represents the leakage permeability of "intact" wells with minimal potential for leakage, and the other mode represents the leakage permeability of "degraded" wells where leakage is likely. The leakage permeabilities in this model ranged from $10^{-15} \mathrm{~m}^{2}$ and $10^{-10} \mathrm{~m}^{2}$. Celia et al. (2011) assigned well leakage permeabilities that range from $10^{-}$ ${ }^{17} \mathrm{~m}^{2}$ to $10^{-11} \mathrm{~m}^{2}$, based on a "soft" scoring method by Watson and Bachu $(2008,2007)$. Those studies also modeled the possibility of poorly completed wells or those where leaking fluids may encounter heterogeneous leakage permeabilities along the length of the well. This was accomplished by assigning different leakage permeabilities to segments along the well. Rather than drawing leakage pathway permeabillities from distributions and allowing these permeabilities to vary along the length of a well, our approach specifies one of four leakage permeabilities for each simulation and assigns this permeability to the entire length of the well. With this approach, we isolate the influence of leakage permeability on the rates and extents of fluids migrating through, and accumulating in, the various aquifers in the stratigraphic sequence. Michigan Sedimentary Basin and Case Study Data

This study focuses on the Michigan sedimentary basin underlying the lower peninsula of Michigan (U.S.A.). Michigan is a water-rich state with abundant surface water and groundwater resources (GCAC, 2006). Approximately 3.2 billion liters per day of groundwater are produced for public (984 million liters per day) and private (950 million liters per day) water supplies, irrigation (750 million liters per day), industrial (337 million liters per day), and other (148 million liters per day) uses. Groundwater supplies a third of the state's total water demand (excepting demand for thermoelectric power cooling), including $37 \%$ of demand for drinking water and 64\% of demand for irrigation (Kenny, et al., 2009). Approximately 400,000 groundwater wells are located throughout the basin and more than $99.5 \%$ are less than $107 \mathrm{~m}$ (350 feet) deep. (See the Supplemental Information.)

There are fifty-seven named sedimentary formations within the Michigan sedimentary basin (Catacosinos et al., 2000). The combined thickness of these formations varies from approximately $1.2 \mathrm{~km}$ (4,000 feet) to over $4.9 \mathrm{~km}$ (16,000 feet). These sedimentary rocks are overlain by as much as $366 \mathrm{~m}$ (1,200 feet) of glacial deposits (Catacosinos et al., 1990). We constructed a three-dimensional topographical model of the strata in the sedimentary basin underlying the lower peninsula of Michigan to represent the depths and thicknesses of all the formations as well as the locations and depths of existing wells. The data sources, interpolation approaches, and the results of the stratigraphic modeling are included in the Supplemental Information. The primary data source is the USGS (Lampe, 2009), which grouped the Michigan basin formations into sixteen hydrostratigraphic units, each of which is classified as an aquifer (higher permeability), a confining unit (lower permeability formation), or a unit with mixed permeability that acts as an aquifer in some locations and a confining unit in others. We used the naming conventions defined by Catacosinos (2000) and the USGS stratigraphy for units above the St. Peter sandstone, but interpolations of the formation depths and locations under Ottawa County were inconsistent with proximal well records. Using oil and gas well data compiled by the Michigan Department of Environmental Quality, we used kriging methods to refine the hydrostratigraphy for the southwestern part of the state. Special approximations were needed for 
the Eau Claire and Mt. Simon because there were not enough wells with data for depths of the tops and bottoms of these formations. Overall, the structure and thickness of formations in our model are consistent with other studies of the Michigan Basin (Barnes, et al., 2009; Catacosinos, et al., 1990; Wickstrom, et al., 2005).

The Mt. Simon and the St. Peter sandstones are the two major target formations for $\mathrm{CO}_{2}$ storage. Together, they are estimated to be able to store as much as $15 \mathrm{GtCO}_{2}(\mathrm{NETL}, 2012)$, which is about 20x the amount of $\mathrm{CO}_{2}$ emitted by electric power plants in Michigan during the decade from 2001 to 2010 (U.S. EPA, 2012). In addition to the 400,000 groundwater wells, approximately 45,000 wells associated with subsurface activities-mostly from oil and natural gas production-penetrate into the basin, roughly 30,000 of which are plugged and abandoned (See Supplemental Information for data sources).

We simulated $\mathrm{CO}_{2}$ injection into the Mt. Simon sandstone beneath the James De Young (JDY) coal-fired power plant, in Ottawa County (western Michigan). Approximately 9.5 $\mathrm{MtCO}_{2} / \mathrm{yr}$ could be captured from JDY and the neighboring J.H. Campbell (JHC) coal-fired power plant (assuming $85 \%$ capacity factor and $90 \%$ capture efficiency). The JDY injection site was chosen for its location relative to these $\mathrm{CO}_{2}$ sources, existing wells that may serve as leakage pathways, and the favorable geophysical characteristics of the Mt. Simon below it. We simulated injection rates of 4,12 , and $20 \mathrm{MtCO}_{2} / \mathrm{yr}$ thereby representing $\mathrm{CO}_{2}$ produced from one, both, or more power plants. We intentionally used these very large injection rates to emphasize leakage and the pressure drive of leaked fluids up the hydrostratigraphic sequence. Figure 1 shows the case study location within a $150 \mathrm{~km}$ x $150 \mathrm{~km}$ section of western Michigan; existing wells are colored by the hydrostratigraphic unit in which they terminate. The JDY site is within $1,740 \mathrm{~m}$ of three clusters of existing UIC Class I injection wells, which contain a total of eight wells (five of which are within $400 \mathrm{~m}$ of the JDY site). All of these wells terminate in the Mt. Simon and may serve as leakage pathways into overlying units.

The three-dimensional model of the Michigan sedimentary basin created for this study captures the bowl-shaped topography of the basin (see Supplemental Information), but the semianalytical leakage estimation model requires an assumption that the units are horizontal, classified as either aquifers aquitards, and with spatially uniform properties. As a consequence, for the geographic extent of the model domain (see Figure 1), an aquifer-aquitard "layer cake" was constructed from the three-dimensional model using the depths, thicknesses, permeabilities, and porosities of each unit directly under JDY, as depicted in Figure 2. Each unit is characterized by a single depth and thickness, which was determined by assessing the permeability of the units in the hydrostratigraphic sequence at the injection location and the presence of nearby subsurface activities. In the layer cake, low permeability units were modeled as aquitards and high permeability units were modeled as aquifers. Where mixed permeability units exist in the hydrostratigraphic unit sequence, the presence of nearby wells terminating in that unit was used to determine if it should be considered to be an aquifer or an aquitard. The unit was modeled as an aquitard in the layer cake if nearby wells did not terminate in that unit, and an aquifer in the layer cake if wells did terminate in the unit. For the purpose of the semi-analytical modeling and the aquifer-aquitard layer cake, if multiple aquifers were stacked on each other in the sequence, these aquifers were combined by summing their thicknesses and using the top-depth of the shallowest aquifer.

The porosities and permeabilities for the units above the Mt. Simon were taken from the three-dimensional model of the Michigan sedimentary basin, where the average porosity and 
permeability of a combined unit is determined from interpolations of data from the USGS (see Supplemental Information). Each aquifer unit in the layer cake, except for the Mt. Simon, is characterized by its own single value for porosity and for permeability. When hydrostratgraphic units were combined to form a single aquifer in the layer cake, the porosity of that aquifer was the average of those of the individual units weighted by thickness. The permeability of these aquifers was the thickness-weighted harmonic average of the permeabilities of the merged units, which is the appropriate average for parallel flow. The Mt. Simon underneath JDY is permeable and porous, and the statistics for these distributions were inferred by regressing data from a nearby well, (API Well 21139000707000).

To explore uncertainty and variability in the geophysical properties of the Mt. Simon formation, probability density functions were constructed to allow these model parameters to be described as stochastic random variables. The probability density function of permeability was assumed to be lognormal as has become common in the field of hydrogeology, but for which the physical reason is ill-defined and for which deviations are numerous (de Marsily et al., 2005). Other $\mathrm{CO}_{2}$ modeling studies have also used lognormal permeability distributions (e.g., Celia et al., 2011; Nogues et al., 2012; Stauffer et al., 2009). Based on the regressions described above, the parameterized $\operatorname{lognormal}$ distributions $-\log \mathrm{N}(\mu, \sigma)$ with the mean $\mu$ being expected value of the permeability and $\sigma$ being its standard deviation — used for our simulations were $\kappa_{\text {unit }}=\log N\left(2.25 \times 10^{-11}, 3.11 \times 10^{-13}\right) \mathrm{m}^{2}$

(1)

for the permeability of the Mt. Simon formation, and

$\phi_{\text {unit }}=\log N(0.13,0.04)$

(2)

for the porosity of the Mt. Simon. The power-law relationship between permeability and porosity in the Mt. Simon was also determined to be:

$$
x_{\text {unit }}=5 \cdot 10^{18} \cdot \phi_{\text {unit }}^{3.911}
$$

with the exponent being not far off from the cubic relationship of the theoretically-based Kozeny-Carman equation. Each simulation was conducted by randomly sampling a value for the porosity from Equation (2) and then the corresponding permeability was calculated from Equation (3). As a consequence, each draw will result in a different reservoir pressure and $\mathrm{CO}_{2}$ plume size (Wainwright et al., 2013) for a given injection rate and assigned leakage permeability.

We examined uncertainty in leakiness by studying four different well leakage permeabilities ( $\left.\kappa_{\text {leak }}\right): 10^{-16} \mathrm{~m}^{2}(0.1 \mathrm{mD}), 10^{-14} \mathrm{~m}^{2}(10 \mathrm{mD}), 10^{-12} \mathrm{~m}^{2}(1 \mathrm{D})$, or $10^{-10} \mathrm{~m}^{2}(100 \mathrm{D})$. Furthermore, each simulation assigned a single value for permeability to every well modeled as a leakage pathway. That is, all well leakage pathways are assumed to be identical in permeability for a given simulation. Thus, rather than treating leakage permeability as a stochastic random variable, this model parameter was treated deterministically, in recognition of the fact that not only do we know very little about this parameter but we know even less about its probability distribution. By investigating leakage permeabilities separately, rather than through Monte Carlo methods employed by previous studies, we were able to discern important characteristics of leakage as a function of these leakage permeabilities. These four discrete values are consistent with measured values of wellbore leakage permeability, which range between $10^{-19} \mathrm{~m}^{2}$ and $10^{-11} \mathrm{~m}^{2}$ (Checkai et al., 2013; Duguid et al., 2013), and the values used in previous probabilistic leakage analyses that 
used the same semi-analytical leakage model (Celia et al., 2011; Nogues et al., 2012). The chosen leakage permeability values were also selected to represent a range that spans the permeabilities of the aquifers represented in the layer cake above the Mt. Simon: the least permeable aquifer has a permeability of $9.21 \times 10^{-17} \mathrm{~m}^{2}$, and the most permeable aquifer has a permeability of $1.93 \times 10^{-12} \mathrm{~m}^{2}$ (Figure 2).

\section{Probabilistic Geophysical Fluid Flow Simulations}

Each simulation was for 30 years of continuous $\mathrm{CO}_{2}$ injection at either 4,12 , or 20 $\mathrm{MtCO}_{2} / \mathrm{yr}$, representing values around the possible $\mathrm{CO}_{2}$ production and capture rate at that location (described above) that are very large relative to likely injection rates. These very large injection rates encourage leakage of substantial quantities of $\mathrm{CO}_{2}$ and, due to the very large pressure drive, brine. For each of the twelve combinations, i.e. each of four well leakage permeability values and each of three injection rates, 100 simulations were conducted with random sampling of the $\phi_{\text {unit }}$, and inferred value of $\kappa_{\text {unit }}$, for the Mt. Simon formation. In addition, we investigated three leakage conditions. In the first condition, the overlying Eau Claire unit serves as a perfect aquitard, with no leakage pathways, and thus $\mathrm{CO}_{2}$ and brine are contained. The second condition models one nearby well that terminates in the Mt. Simon-a single UIC Class I well within $300 \mathrm{~m}$ of the injection location-as the only potential leakage pathway out of the Mt. Simon. The third leakage condition models all wells as potential leakage pathways.

The model domain was $200 \mathrm{~km}$ radial from the injection location. For the modeled geothermal gradient at our case study location, we used data for a nearby well contained in the SMU Geothermal Database as reported to the National Geothermal Database System (NGDS, 2014; SMU, 2015). That geothermal gradient in that well was measured to be $12{ }^{\circ} \mathrm{C} / \mathrm{km}$. We used an $8^{\circ} \mathrm{C}$ mean annual surface temperature in combination with this geothermal gradient to determine the temperature at depth. $\mathrm{CO}_{2}$ density and viscosity were estimated using data from Span and Wagner (1996). Similarly, brine density and viscosity were estimated based on the relationships in Rowe and Chou (1970) and Kestin and Shankland (1984), respectively, assuming hydrostatic at depth, as well as the total dissolved solids (TDS) in the brine (Lampe, 2009).

Since each simulation uses a different set of geophysical parameters for the Mt. Simon, each simulation has a different amount of $\mathrm{CO}_{2}$ and brine leaking from the storage reservoir as well as different spatial extents of the plumes and pressure increases within the storage reservoir and in the overlying aquifers into which these fluids leak. In a given simulation, the semi-analytical leakage model estimates for every aquifer over time and aerial space: the percentage of the aquifer thickness that contains $\mathrm{CO}_{2}$ and the increase of brine pressure above hydrostatic. In this work, simulation output was recorded at annual intervals on a $1 \mathrm{~km}$ by $1 \mathrm{~km}$ grid for a $150 \mathrm{~km} \mathrm{x}$ $150 \mathrm{~km}$ portion of the model domain (Figure 1). We did not record output for the area under Lake Michigan because it lacks existing wells that can serve as leakage pathways. For each aquifer, we calculated maximum, minimum, and average values of each of the output data for each time step. For each of the twelve scenarios, we also calculated the probability of $\mathrm{CO}_{2}$ being present and the probability of a brine pressure increase for each location on the recording grid at each time step. These probabilities were estimated by calculating the percentage of simulations in which $\mathrm{CO}_{2}$ is present, or the brine pressure is elevated, across all 100 simulations. For each aquifer in each time step, we also used the aggregate $\mathrm{CO}_{2}$ mass across the entire aquifer to determine the total amount of $\mathrm{CO}_{2}$ in each aquifer over time. 


\section{Results}

Leaked $\mathrm{CO}_{2}$ and Brine Pressure Perturbation

This section presents the simulation results of $\mathrm{CO}_{2}$ injection and leakage for one scenario, to explain the physical processes and to demonstrate model output, as depicted in Figure 5. Due to buoyancy, injected $\mathrm{CO}_{2}$ rises to the top of the formation where it is trapped by the aquitard and spreads horizontally. The pressure created from $\mathrm{CO}_{2}$ injection into the Mt. Simon formation causes fluid to leak to the Galesville formation. Initially only brine leaks but when the $\mathrm{CO}_{2}$ plume is big enough to reach the leaky wells located west of the injection point, then $\mathrm{CO}_{2}$ begins to leak. Since our methodology uses values for the porosity and the permeability of the Mt. Simon that are drawn from distributions, as well as the discrete values for the leakage permeabilities, each simulation produces a unique profile for the $\mathrm{CO}_{2}$ plume and for the distribution of the brine pressure increase in the Mt. Simon and the overlying aquifers into which fluids leak. Figure 5 shows the maximum, minimum, and average profiles of the $\mathrm{CO}_{2}$ plumes and of the brine pressure increases in the Mt. Simon and Galesville formations after 30 years of 20 $\mathrm{MtCO}_{2} / \mathrm{yr}$ injection averaged over all 400 simulations covering the four different leakage permeabilities.

In Figure 5, the $\mathrm{CO}_{2}$ plume in the Mt. Simon extends at least $4.3 \mathrm{~km}$ from the injection well to a maximum of $7.3 \mathrm{~km}$ from the injection well, whereas the plume in the Galesville into which $\mathrm{CO}_{2}$ leaks extends a maximum of only $4.6 \mathrm{~km}$ from the injection well. The $\mathrm{CO}_{2}$ plumes in the Mt. Simon are mostly symmetric around the injection well, but leakage into the Galesville through the injection well and the cluster of nearby UIC Class I disposal wells to the west results in more mass to the west of the injection well.

The Galesville formation is relatively thin, permeable, and porous when compared to the other subsurface aquifers. As a consequence, the pressure perturbation extends horizontally to a relatively large radius and $\mathrm{CO}_{2}$ can accumulate in the Galesville formation. Pressure increase here leads to further leakage upward to the Trenton-Black River/St. Peter formation and the Travers-Dundee/Silurian-Devonian formation. 
Figure 5 shows how the increases in brine pressure decrease with the distance from the injection well, diminishing the driving force for leakage. For example, the average brine pressure increase has decreased from 28.30 MPa to 11.16 MPa one km east of the injection well, whereas the maximum has decreased from 93.64 MPa to $32.21 \mathrm{MPa}$. At a distance five $\mathrm{km}$ from the injection well, these brine pressure increases have decreased to $14.29 \mathrm{MPa}(\max )$ and $6.5 \mathrm{MPa}$ (ave). Figure 5 also shows that the increase in brine pressures are not radially symmetric around the injection well. The profiles in the Mt. Simon decrease more quickly to the east of the injection well than to the west. This asymmetry is due to pressure relief from the nearby leaky wells west of the injection well as fluid is being transferred up. While the pressure increase in the Galesville is approximately two orders of magnitude less than in the Mt. Simon, this transfer of pressure is apparent in the profiles in the Galesville formation, which peaks $1 \mathrm{~km}$ west of the injection location.

The hydrostatic pressure at the top of the Mt. Simon is $16.78 \mathrm{MPa}$. The maximum brine pressures exceed this until $4.5 \mathrm{~km}$ east of the injection location, whereas the average of the brine pressures exceed this until $0.3 \mathrm{~km}$ east of the injection well. These distances are less than the extents of the respective $\mathrm{CO}_{2}$ plumes. Therefore, the size of the $\mathrm{CO}_{2}$ plume defines the extent of the AoR in these simulations.

Leakage and $\mathrm{CO}_{2}$ Accumulation Rates in the Aquifer Sequence

Figure 7 shows the amounts of $\mathrm{CO}_{2}$ that accumulate per year in each aquifer averaged over 30 years of continuous injection and leakage, and relates these simulated results to observations of natural $\mathrm{CO}_{2}$ leakage at five locations worldwide.

The results are plotted so that the markers appear halfway through the thickness of each aquifer. Line and marker types distinguish between injection rates (dotted line with diamond marker, 4 $\mathrm{MtCO}_{2} / \mathrm{yr}$; dashed line with triangle marker, $12 \mathrm{MtCO}_{2} / \mathrm{yr}$; solid line with circle marker, 20 $\mathrm{MtCO}_{2} / \mathrm{yr}$ ). (A) shows the average over all leakage permeabilities for each injection rate and the relation to natural analogs for $\mathrm{CO}_{2}$ leakage: (a) Laacher See, (b) Crystal Geyser, (c) Albany Hill, (d) Mammoth Mountain, (e) Solfatara (from Lewicki et al., 2006), where hollow markers are extrapolated from the data; (B) shows the average of the results of the 100 simulations for the individual leakage permeabilities for each injection rate

The rate at which $\mathrm{CO}_{2}$ leaks into the overlying aquifers increases with the injection rate, but even though the injection rates are very large, this effect is far smaller than the effect of variation in $\kappa_{\text {leak}}$. The leakiest well permeability $\left(\kappa_{\text {leak }}=10^{-10} \mathrm{~m}^{2}\right)$ clearly results in the most leakage throughout the sequence. Even when $\kappa_{\text {leak }}$ is very high $\left(10^{-10} \mathrm{~m}^{2}\right)$ the annual $\mathrm{CO}_{2}$ accumulation rate in overlying aquifers decreases by approximately one order of magnitude per aquifer. In the USDW (shallowest aquifer), the accumulation rate is four orders of magnitude less than in the Mt. Simon. For lower leakage permeabilities, aside from the accumulation rate in the Galesville aquifer overlying the Mt. Simon when $\kappa_{\text {leak }}=10^{-12} \mathrm{~m}^{2}$-where between $4,477 \mathrm{tCO}_{2} / \mathrm{yr}(4$ $\mathrm{MtCO}_{2} / \mathrm{yr}$ injection) and 20,416 $\mathrm{tCO}_{2} / \mathrm{yr}\left(20 \mathrm{MtCO}_{2} / \mathrm{yr}\right.$ injection $)$ accumulates on average- the amount of $\mathrm{CO}_{2}$ amassing in the aquifers above the Mt. Simon is negligible in comparison, despite the very large injection rates. At most, $183 \mathrm{tCO}_{2} / \mathrm{yr}$ is entering the USDW (shallowest aquifer) when $\kappa_{\text {leak }}=10^{-12} \mathrm{~m}^{2}$. There is a two-order of magnitude reduction in the amount of $\mathrm{CO}_{2}$ in each aquifer from $\kappa_{\text {leak }}=10^{-12} \mathrm{~m}^{2}$ to $\kappa_{\text {leak }}=10^{-14} \mathrm{~m}^{2}$, and another two-order of magnitude reduction from $\kappa_{\text {leak }}=10^{-14} \mathrm{~m}^{2}$ to $\kappa_{\text {leak }}=10^{-16} \mathrm{~m}^{2}$. 
The curves in Figure 7 show two more trends that highlight the complicated interaction between leakage permeability, aquifer permeability, porosity, thickness, and the density and viscosity of $\mathrm{CO}_{2}$ in determining the relative amounts of $\mathrm{CO}_{2}$ migrating vertically and leaking into an aquifer or migrating horizontally within an aquifer in which it accumulates. In this case study, the accumulations for different injection rates converge higher in the geologic sequence, so that there is a wider range in the amount of $\mathrm{CO}_{2}$ accumulating within deeper aquifers than within shallower aquifers. Such convergence suggests that the fluid flow and aquifer capacity-as determined by permeability, porosity, and thickness - constrain the amount of $\mathrm{CO}_{2}$ that will migrate to overlying aquifers. Second, Figure 7 shows "elbows" in the curves for $\mathrm{CO}_{2}$ accumulation in the Trenton-Black River / St. Peter for $\kappa_{\text {leak }}=10^{-12}, 10^{-14}$, and $10^{-16} \mathrm{~m}^{2}$, but not for $\kappa_{\text {leak }}=10^{-10} \mathrm{~m}^{2}$. Both $\kappa_{\text {leak }}=10^{-10} \mathrm{~m}^{2}$ and $\kappa_{\text {leak }}=10^{-12} \mathrm{~m}^{2}$ are more permeable than the aquifers, but only the curve for $\kappa_{\text {leak }}=10^{-12} \mathrm{~m}^{2}$ has an elbow. When $\kappa_{\text {leak }}=10^{-10} \mathrm{~m}^{2}$, the flow of leaking $\mathrm{CO}_{2}$ from below is sufficient to drive $\mathrm{CO}_{2}$ into the Trenton-Black River / St. Peter, even though it is the least porous aquifer in the sequence. At lower leakage permeabilities, $\left(\kappa_{\text {leak }}=10^{-}\right.$ ${ }^{12}, 10^{-14}$, and $10^{-16} \mathrm{~m}^{2}$ ), the relative effects of the well leakage permeability, the aquifer permeability, and the aquifer porosity become more apparent, and the porosity of the TrentonBlack River / St. Peter becomes a constraint and $\mathrm{CO}_{2}$ generally passes through it to shallower aquifers. This migration is driven partly by its buoyancy, which accelerates as its density decreases while it rises. The density of $\mathrm{CO}_{2}$ at the bottom of the Galesville aquifer is $877 \mathrm{~kg} / \mathrm{m}^{3}$, whereas it is $863 \mathrm{~kg} / \mathrm{m}^{3}$ at the top of the Trenton-Black River / St. Peter. $\mathrm{CO}_{2}$ enters the bottom of the Travers-Dundee / Silurian-Devonian as a liquid with a density of $858 \mathrm{~kg} / \mathrm{m}^{3}$, but the $\mathrm{CO}_{2}$ that rises to the top of this aquifer will become a gas as its density will decrease by a factor of 7.7 to $112 \mathrm{~kg} / \mathrm{m}^{3}$. Despite being less permeable than the Trenton-Black River / St. Peter below it, more $\mathrm{CO}_{2}$ accumulates in the Traverse-Dundee / Silurian-Devonian in part due to the higher porosity and greater thickness of this aquifer. The porosity and thickness more than compensate for the substantial difference in the density between the $\mathrm{CO}_{2}$ at the bottom of the TraverseDundee / Silurian-Devonian and the $\mathrm{CO}_{2}$ at the top of it.

The inset in Figure 7(A) shows data for natural $\mathrm{CO}_{2}$ seepage (Lewicki et al., 2006). The solid markers indicate observed data, which includes data for Albani Hill where the rate of surface leakage and groundwater accumulation is measured. We use this Albani Hills relationshipwhere $184,690 \mathrm{tCO}_{2} / \mathrm{y}$ reaches groundwater and only $1 / 7$ of that amount, $27,010 \mathrm{tCO}_{2} / \mathrm{y}$, reaches the surface - to extrapolate our simulation results to the surface and the analogs to the groundwater aquifer (Table 1). While this study extrapolates these values as if seepage to the surface occurred at the same point of time as it enters the groundwater, studies have shown that it can take several years before a leak that entered the saturated zone reaches the surface (Ogretim et al., 2014). Our findings show that, even with very large injection rates, $\mathrm{CO}_{2}$ leakage into the shallow groundwater aquifer is always less than the leakage from the natural analogs, either measured or extrapolated. The simulated leakage is at most $2 \%$ of the $\mathrm{CO}_{2}$ being released by analogs. If all of the wells have the highest leakage permeability $\left(10^{-10} \mathrm{~m}^{2}\right)$, the rate at which $\mathrm{CO}_{2}$ enters the groundwater aquifer is at most $6.1 \%$ of the (extrapolated) amount at Laacher See. It is not our intent to imply that the rates of natural $\mathrm{CO}_{2}$ seepage are inconsequential, and that by extension the simulated rates are negligible. Rather, this comparison helps to put the simulated leakage rates in context with known values. This comparison also highlights the positive role that porous and permeable layers above the storage reservoir may have in attenuating leakage. These natural analogs have volcanic, geothermal, and sedimentary origins where these intervening layers may be absent or already be filled with $\mathrm{CO}_{2}$ (Lewicki et al., 2006). 
The two aquifers of concern are the Galesville - where the majority of leaked $\mathrm{CO}_{2}$ will accumulate because it is permeable and porous (Sun et al., 2013) - and the shallow groundwater aquifers-Quaternary to Marshall-where the USDW is located. For these two aquifers, Figure 9 shows the 400 simulated values of total $\mathrm{CO}_{2}$ accumulation after 30 years of continuous injection and leakage, represented as cumulative distribution plots. The major difference is that the range of possible values for $\mathrm{CO}_{2}$ accumulation in the Galesville (spanning nine orders of magnitude) is much larger than the range in the shallow aquifer (spanning six orders of magnitude). In the Galesville, variation in values of the porosity and permeability of the Mt. Simon produce a range of two orders of magnitude in $\mathrm{CO}_{2}$ accumulation for each value of $\kappa_{\text {leak }}$, and the curves differ by injection rate. In the shallow aquifer, where the results of each injection rate tend to lie on top of each other, variation is entirely explained by the value of $\kappa_{\text {leak }}$ with variation the Mt. Simon properties having negligible effect. The amount of $\mathrm{CO}_{2}$ that accumulates depends on the injection rate more in the deeper aquifer than it does in the shallower aquifer. This convergence was also evident in Figure 7, where the range between the average amount accumulating in a 4 $\mathrm{MtCO}_{2} / \mathrm{yr}$ injection and a $20 \mathrm{MtCO}_{2} / \mathrm{yr}$ injection is tighter in the shallow aquifer than it in in the deep aquifer.

\section{Leakage and the U.S. DOE Storage Permanence Goal}

Figure 11 shows the temporal evolution of the total amount of $\mathrm{CO}_{2}$ that leaks from the storage reservoir as a percentage of $\mathrm{CO}_{2}$ that has been injected. For all three injection rate scenarios, the highest well leakage permeability $\left(\kappa_{\text {leak }}=10^{-10} \mathrm{~m}^{2}\right)$ violates the goal, but the goal is never violated when $\kappa_{\text {leak }}$ is $10^{-12} \mathrm{~m}^{2}$ or less. If all of the existing wells have a leakage permeability of $\kappa_{\text {leak }}=10^{-12} \mathrm{~m}^{2}$, in the first year between $0.03 \%$ and $0.05 \%$ of the injected $\mathrm{CO}_{2}$ leaks out of the reservoir, on average. After 30 years, the cumulative amount of $\mathrm{CO}_{2}$ that has escaped from the reservoir grows to between $0.09 \%$ and $0.11 \%$ of the total amount of $\mathrm{CO}_{2}$ injected. Leakage is about two orders of magnitude greater when the wells leak with a permeability of $\kappa_{\text {leak }}=10^{-10} \mathrm{~m}^{2}$, failing to meet the $1 \%$ U.S. DOE goal. These results suggest the wellbores within the AoR in this case study have a threshold permeability; as long as $\kappa_{\text {leak }}$ is $10^{-12}$ $\mathrm{m}^{2}$ or less, regardless of the injection rate, leakage from the Mount Simon formation at this particular injection location would conform to the U.S. DOE storage permanence goal.

For the average of the simulations for all four values of $\kappa_{\text {leak }}$, the simulated leakage for the 4 $\mathrm{MtCO}_{2} / \mathrm{y}$ injection rate is always above the $1 \%$ leakage threshold, but the simulated leakage from the even higher injection rates are initially below the $1 \%$ threshold. These results indicate that leakage of up to $594,000 \mathrm{tCO}_{2}$-after five years of a $12 \mathrm{MtCO}_{2} / \mathrm{yr}$ injection or three years of a $20 \mathrm{MtCO}_{2} / \mathrm{yr}$ injection-is allowable, but leakage of $50,400 \mathrm{tCO}_{2}$ after one year of a $4 \mathrm{MtCO}_{2} / \mathrm{yr}$ injection is not.

The lowest injection rate always has the highest percentage of injected $\mathrm{CO}_{2}$ that leaks-a finding that is not solely a result of the lower denominator but also relates to site characteristics. For example, in terms of the percentage of the total amount of $\mathrm{CO}_{2}$ present in the aquifer, the 4 $\mathrm{MtCO}_{2} / \mathrm{yr}$ injection rate is $19 \%$ of that of the $20 \mathrm{MtCO}_{2} / \mathrm{yr}$ injection rate in Galesville, $47 \%$ in Trenton-Black River / St. Peter, 94\% in Traverse-Dundee / Silurian-Devonian, and $84 \%$ in the shallowest aquifer. The U.S. DOE goal of at most $1 \%$ leakage is exceeded in our results when every well in the basin is modeled as a potential leakage pathway, but never when only the nearby well leaks. This percentage-based performance goal is biased against lower injection rates. Leakage is a higher percentage of injection for lower injection rates than it is for higher 
injection rates, and thus more $\mathrm{CO}_{2}$ can leak out without violating the storage permanence goal when more is injected. Consequently, larger environmental and financial consequences of leakage may be incurred while still conforming to the DOE goal.

\section{Leakage and the Area of Review}

In all of the simulations, the increase in brine pressure extends far outside of the $\mathrm{CO}_{2}$ plume, but the increase in brine pressure that is sufficient enough to drive fluid upward into the USDW only occurs within close proximity to the injection well and is always within the spatial extent of the $\mathrm{CO}_{2}$ plume in the Mt. Simon formation. As a consequence, in this case study, the spatial extent of the AoR is defined by the presence of $\mathrm{CO}_{2}$ in the Mt. Simon at this injection site. Considering all 400 simulations per injection rate and leakage condition collectively, "spatial probabilities" of $\mathrm{CO}_{2}$ being present were calculated for a $1 \mathrm{~km}$ grid in the $150 \times 150 \mathrm{~km}$ modeled region. Using these probabilities, Figure 12 provides summaries of the sizes of the simulated $\mathrm{CO}_{2}$ plumes in the Mt. Simon after 30 years of injection. Figure 12(a) shows a map view of the $\mathrm{CO}_{2}$ plume for the $20 \mathrm{MtCO}_{2} / \mathrm{yr}$ injection rate for the case where all of the wells leak. The median value of the plume radius - where the probability of $\mathrm{CO}_{2}$ being present is greater than $50 \%$ within the radius and less than $50 \%$ outside of the radius-is indicated. Figure 12(b) shows how injection rate and well leakage scenarios affect the probability of $\mathrm{CO}_{2}$ being present at different distances east of the injection location.

Figure 12 provides evidence that leakage that transfers some $\mathrm{CO}_{2}$ into overlying formations may reduce the AoR, similar to the reduction in the footprint of $\mathrm{CO}_{2}$ that can be achieved by stacked storage systems where $\mathrm{CO}_{2}$ is intentionally injected into multiple zones. For a given distance from the injection well, the probability of $\mathrm{CO}_{2}$ being present when all wells leak (dotted lines) is nearly always less than the probability when no wells leak (solid line) and when only one well leaks (dashed lines). The exception is for the $12 \mathrm{MtCO}_{2} / \mathrm{yr}$ injection rate in which the probability of $\mathrm{CO}_{2}$ being present when one well leaks is less than when no wells leak. This is true until $6 \mathrm{~km}$ east of the injection location, where the $\mathrm{CO}_{2}$ plume extended this far in $7 \%$ of the simulations with one leaking well but only $3 \%$ of the simulations with no leakage. In contrast, for the $4 \mathrm{MtCO}_{2} / \mathrm{yr}$ and $20 \mathrm{MtCO}_{2} / \mathrm{yr}$ injection rates, the probability of $\mathrm{CO}_{2}$ being present is greater when one well leaks than it is when no wells leak until $4 \mathrm{~km}$ and $7 \mathrm{~km}$ east of the injection location, where $6 \%$ and $13 \%$ of the simulations had $\mathrm{CO}_{2}$ plumes that extended this far for the $4 \mathrm{MtCO}_{2} / \mathrm{yr}$ and $20 \mathrm{MtCO}_{2} / \mathrm{yr}$ injection rates, respectively.

The above descriptions are based on a single transect extending to the east of the injection well, at only one point at the end of $\mathrm{CO}_{2}$ injection. Figure 14 shows the consistency of the expected reductions in the AoR over all of the years of $\mathrm{CO}_{2}$ injection and leakage and over all of the locations where $\mathrm{CO}_{2}$ is present, and thus defining the AoR. If the probability of $\mathrm{CO}_{2}$ being present at a location is less with leakage than it is without leakage in the same year of the simulation, then this location is less likely to have $\mathrm{CO}_{2}$ with leakage than it is without leakage. Aggregating these differences over all of the locations where $\mathrm{CO}_{2}$ may be present without leakage (i.e., the two-dimensional footprint of the AoR without leakage) will indicate the expectation of how much the AoR may be reduced due to leakage. Figure 14 shows these differences in the spatial probabilities of $\mathrm{CO}_{2}$ being present throughout the formation by comparing the probabilities when all wells leak with those without leakage for each year of the simulation. The left column shows the portion of the locations where leakage reduced the probability that $\mathrm{CO}_{2}$ is present, and the right column shows the average and standard deviation of the differences in these probabilities 
The bars in Figure 14 show the percentage of the locations where the probability of $\mathrm{CO}_{2}$ being present is reduced due to leakage. If leakage reduces the AoR, the bars will occupy more than $50 \%$ of the $\mathrm{Y}$-axis, which is clearly the case in Figure 14; there is only one situation after the first year of injection where the results indicate that $\mathrm{CO}_{2}$ is more likely to be present with leakage than without it (Year 7, $12 \mathrm{MtCO}_{2} / \mathrm{yr}$ injection). There are only two cases where the results show the percentage of the area where these probabilities are equal (Year 1, $20 \mathrm{MtCO}_{2} / \mathrm{yr}$; Year 3, $12 \mathrm{MtCO}_{2} / \mathrm{yr}$ ). There are no bars for years one and two in the $4 \mathrm{MtCO}_{2} / \mathrm{yr}$ injection because the probabilities were equal throughout the $\mathrm{CO}_{2}$ plume. When only one well leaks (not shown), six of the years in the $20 \mathrm{MtCO}_{2} / \mathrm{yr}$ injection indicate more locations had an increase in the probability of $\mathrm{CO}_{2}$ being present than a decrease in this probability. The bars in Figure 14 indicate that leakage may reduce the AoR (bars are greater than 50\%) when all of the wells leak for every year for the $4 \mathrm{MtCO}_{2} / \mathrm{yr}$ and the $20 \mathrm{MtCO}_{2} / \mathrm{yr}$ injection rates and for 28 of the 30 years for the $12 \mathrm{MtCO}_{2} / \mathrm{yr}$ injection rate. This is also the case for five years in the $4 \mathrm{MtCO}_{2} / \mathrm{yr}$ injection rate, seven years in the $12 \mathrm{MtCO}_{2} / \mathrm{yr}$, and 21 years for the $20 \mathrm{MtCO}_{2} / \mathrm{yr}$ injection rate when only the nearest well leaks (not shown). In addition, seven years are equal for the $4 \mathrm{MtCO}_{2} / \mathrm{yr}$ injection rate, three years are equal for the $12 \mathrm{MtCO}_{2} / \mathrm{yr}$ injection rate, and two years are equal for the $20 \mathrm{MtCO}_{2} / \mathrm{yr}$ injection rate. Overall, the left column of Figure 14 indicates that the expected reduction in the AoR is consistent over time.

This consistency in the expected reduction in the AoR is also shown in the right column in Figure 14, which shows the average of the difference in the spatial probabilities of $\mathrm{CO}_{2}$ being present for each year. This difference is calculated by subtracting the probability that $\mathrm{CO}_{2}$ is present when leakage occurs from the probability that $\mathrm{CO}_{2}$ is present without leakage for each location where these probabilities are different, and the average is calculated over all of these locations. If leakage reduces the AoR, this average difference should be positive, which is clearly the case when all of the wells leak, regardless of the injection rate. This positive difference is also the case for the $12 \mathrm{MtCO}_{2} / \mathrm{yr}$ injection rate when only one well leaks (not shown). The majority of these averages are more than one standard deviation from zero when all of the wells leak, but for the $12 \mathrm{MtCO}_{2} / \mathrm{yr}$ injection when only one well leaks, most of the positive averages are within one standard deviation of zero. For the $4 \mathrm{MtCO}_{2} / \mathrm{yr}$ and $20 \mathrm{MtCO}_{2} / \mathrm{yr}$ injection rates, the averages of the differences are negative, but they are much closer to zero (which is well within one standard deviation) than the results where the average of the differences in probabilities is positive. The differences in the probabilities shown in the right column of Figure 14 are positive, small, and consistent over time; trendlines indicate that they average approximately $2.5 \%$ over all of the years for the $4 \mathrm{MtCO}_{2} / \mathrm{yr}$ injection rate, and for the 12 $\mathrm{MtCO}_{2} / \mathrm{yr}$ and $20 \mathrm{MtCO}_{2} / \mathrm{yr}$, respectively, injection rates the differences in the probabilities increase from about $3 \%$ and $4 \%$ in the early years to about $5 \%$ and $7 \%$ after 30 years. Overall, Figure 14 indicates that leakage can serve a function to reduce the AoR, where the magnitude of this reduction in the footprint may be small and consistent.

\section{U.S. EPA Class VI Rule and U.S. DOE Guideline for Storage Permanence}

In contrast to the U.S. DOE storage permanence goal, which allows for some leakage from the storage reservoir, the U.S. EPA Class VI rule prohibits leakage into USDWs in part by requiring operators to address all potential leakage pathways within the AoR2. As leaked $\mathrm{CO}_{2}$ migrates upward, its density decreases faster than the decrease in brine hydrostatic pressure, especially near the top of the Traverse-Dundee / Silurian-Devonian, at a depth around $510 \mathrm{~m}$, when it transitions from a liquid with a density of $531 \mathrm{~kg} / \mathrm{m}^{3}$ to a vapor with density $155 \mathrm{~kg} / \mathrm{m}^{3}$ 
(Span and Wagner, 1996). As a result, the buoyant drive toward a USDW increases as leaked $\mathrm{CO}_{2}$ migrates upward, but structural trapping along the way may limit the amount that reaches the USDW.

The results for this case study show that, even with very large injection rates, most of the leaked $\mathrm{CO}_{2}$ will be trapped underneath aquitards that exist in the stratigraphic sequence between the reservoir caprock and the USDW, but Figure 7 and Figure 9 indicate that some $\mathrm{CO}_{2}$ will reach the USDW. In all of the simulations, leaked $\mathrm{CO}_{2}$ reached the USDW in the first year regardless of the condition and of the well leakage permeabilities. Figure 7 shows that the average $\mathrm{CO}_{2}$ accumulation rates in each aquifer after 30 years converge shallower in the stratigraphic sequence and become insensitive to the injection rate. This convergence is also evident in the first year of injection when $687 \mathrm{tCO}_{2}$ reach the USDW when only one well leaks regardless of the injection rate. Similarly, when all of the wells leak, 2,032 $\mathrm{tCO}_{2}$ reaches the USDW for the $4 \mathrm{MtCO}_{2} / \mathrm{yr}$ injection rate, 2,059 $\mathrm{tCO}_{2}$ for the $12 \mathrm{MtCO}_{2} / \mathrm{yr}$, and 2,080t $\mathrm{MtCO}_{2} / \mathrm{yr}$ for the $20 \mathrm{MtCO}_{2} / \mathrm{yr}$ injection rates. When limited to the 300 simulations when $\kappa_{\text {leak }}$ was $10^{-12} \mathrm{~m}^{2}$ or less - the situations when the leakage does not violate the U.S. DOE Storage Permanence goal-only $9 \mathrm{tCO}_{2}$ on average reaches the USDW when one well leaks and only $27 \mathrm{tCO}_{2}$ on average reaches the USDW when all wells leak. These simulations suggest that a $\mathrm{CO}_{2}$ storage operation wherein any $\mathrm{CO}_{2}$ leaks from a storage reservoir, regardless of whether or not it meets the U.S. DOE storage permanence goal, would be in violation of the current U.S. EPA Class VI rule if the leakage that reaches the USDW is detected.

\section{Conclusions}

In this work, we investigated the potential for leakage from geologic $\mathrm{CO}_{2}$ storage reservoirs in the context of the U.S. DOE goal of $99 \%$ storage permanence and the U.S. EPA Class VI rule that prohibits leaked fluids from entering USDW aquifers. Through basin-scale simulations of very large $\mathrm{CO}_{2}$ injection rates into the Mt. Simon formation underlying Ottawa County in Michigan, we estimated the extent to which fluids might leak through wellbores and migrate to shallower formations. This work demonstrated how site-specific characteristics combine in complex ways to determine leakage potential and its geospatial variation, how existing wells affect leakage depending on their leakage permeability and their location within the AoR, and how operational parameters such as injection rate impact leakage potential.

This work is a sensitivity study to understand the degree to which important parameters influence leakage. The model we used has a number of simplifying assumptions for computational tractability that allows us to conduct probabilistic analyses for risk assessments of layered sedimentary systems that do not already contain $\mathrm{CO}_{2}$, but these simplifications reduce the reliability of the results for predicting or comparing actual leakage rates at real locations. The model will produce leakage whenever $\mathrm{CO}_{2}$ encounters a leakage pathway or the increase in brine pressure at a leakage pathway is sufficient to overcome the difference in hydrostatic pressure between aquifers. The simplifications in the model also neglect a number of important subsurface conditions (e.g., reservoir heterogeneity, aquifer dip) and physical processes (e.g., geochemistry) that will affect plume migration, flow paths, and leakage rates. The aquiferaquitard layer cake also highly simplifies the subsurface with distinct and uniform contrasts between permeable aquifers, impermeable aquitards, and permeable leakage pathways that can represent wells but not other subsurface characteristics (e.g., faults). While these simplifications limit the model's applicability to real systems, they allow us to focus on important general characteristics of leakage and its implications. 
For this case study, an important finding is that the extent of horizontal migration of brine and $\mathrm{CO}_{2}$ into porous formations overlying the Mt. Simon can greatly reduce $\mathrm{CO}_{2}$ flux to shallower drinking water aquifers. Even though every simulation resulted in some amount of leakage reaching the USDW aquifer, the accumulation rate in the shallow aquifer was orders of magnitude less than the rate at which fluids leaked from the storage formation. Horizontal spreading into intervening porous formations underneath each aquitard can provide additional stratigraphic trapping of $\mathrm{CO}_{2}$. This effect could be considered to be similar to a stacked storage projects, where multiple overlying zones are intentionally used to store $\mathrm{CO}_{2}$.

We found that large variations in Mt. Simon formation properties and injection rates produced negligible variation in $\mathrm{CO}_{2}$ accumulation rates near the land surface and had little effect on the likelihood of satisfying the U.S. DOE storage permanence goal. The well leakage permeability was in fact the most important variable determining leakage processes. Furthermore, to achieve substantial leakage rates in these simulations required the unrealistic scenario that all wells penetrating the primary caprock seal were leaky wells at the anomalously high permeability of $10^{-10} \mathrm{~m}^{2}$.

In the context of our case study, we also investigated implications of the U.S. DOE goal for storage permanence to keep leakage below $1 \%$ of the $\mathrm{CO}_{2}$ injected. We focused on the operational timeframe wherein leakage can be attenuated by multiple permeable layers above the target reservoir. We do not consider important issues pertaining to the amounts that may leak after active injection and the migration of all leaked fluids over longer timeframes. Leakage may continue to migrate upward over time and numerous physical and chemical processes that may attenuate or amplify that leakage. These possibilities suggest that the risk to USDWs and the climate due may continue to evolve after $\mathrm{CO}_{2}$ injection ends. One previous study indicated that leakage would always be below $1 \%$ of $\mathrm{CO}_{2}$ injected with $95 \%$ confidence in a range of parameters for that case study (Nogues et al., 2012). We showed that U.S. DOE percentagebased metric could be biased against lower injection rates: a much larger quantity of $\mathrm{CO}_{2}$ can leak from higher injection rates than lower ones and stay below the storage permanence goal. For one set of simulation parameters, the simulations resulted in the lowest injection rate never being in compliance with the storage permanence goal, whereas the leakage from the higher injection rate was below the storage permanence goal for a few years. One option could be to base rules and guidelines on allowable quantities of leakage, in absolute terms. For example, at most 100,000 tonnes of $\mathrm{CO}_{2}$ could leak from the target reservoir. This fixed amount would remove the bias against low injection rates, but it would be more stringent for project with large injection rates. Such a metric would have a tendency to equalize the potential externalities of leakage across projects of varying sizes, and thus emphasize the importance of environmental and human health protection-one goal of U.S. EPA regulation. Since the physical parameters of potential storage reservoirs-such as permeability, porosity, thickness, and their associated heterogeneities-will result in an array of potential $\mathrm{CO}_{2}$ storage projects with a wide range of capacities and feasible injection rates, more nuanced guidelines could be constructed to reduce impediments imposed by the way metrics are constructed. The ultimate goal of CCS is to keep $\mathrm{CO}_{2}$ out of the atmosphere, and being able to develop and operate numerous storage projects without being constrained by biases such as these may encourage their deployment. The success of geologic $\mathrm{CO}_{2}$ storage as a viable option for reducing $\mathrm{CO}_{2}$ emissions to the atmosphere will be the product of a number of concerns, including the ability to develop projects and the degree to which projects may continue to inject $\mathrm{CO}_{2}$ or forced to be close after leakage occurs. 
We demonstrated some benefits that may accompany leakage into overlying porous formations. The reduction in brine pore pressure in the storage formation that accompanies leakage reduces the driving force for further fluid migration. This is analogous to the engineered strategy of reducing leakage potential through active brine production from storage formations (Birkholzer et al., 2012; Buscheck et al., 2012; Hosseini and Nicot, 2012) or heat extraction to provide a thermal barrier to deliberately contain fluids within the reservoir (Randolph et al., 2013). We showed that the transfer of fluids up the sequence can reduce the extent of the $\mathrm{CO}_{2}$ plume, and hence the size of the AoR. In this study, the AoR was always defined by the extent of the $\mathrm{CO}_{2}$ plume in the storage reservoir and was, on expectation, greater than the AoR stipulated for U.S. EPA UIC Class I and Class II wells. Since $\mathrm{CO}_{2}$ injection operators are required under U.S. EPA UIC Class VI rules to assess the potential leakage pathways within the AoR, leakage could reduce expenses related to such assessments and thus contribute to the financial viability of a $\mathrm{CO}_{2}$ storage operation. A smaller AoR at a location will likely require less time, effort, and money by the project developers and by regulators to investigate potential leakage pathways during site characterization and during subsequent reassessments in the operational and postoperational periods. A smaller AoR could thus require less resources to develop and oversee a $\mathrm{CO}_{2}$ storage project, and thus increase the possibility that a CCS project could be deployed."

Policy for geologic $\mathrm{CO}_{2}$ storage must be developed to achieve the intended goals with careful consideration of the physical processes it governs. Some policy-such as the U.S. DOE storage permanence goal-will incorporate goals that seek to advance the efficacy of $\mathrm{CO}_{2}$ storage as a climate change mitigation technology by allowing some $\mathrm{CO}_{2}$ to leak from a storage reservoir. Other policy will seek to limit the potential for undesired consequences, such as the U.S. EPA Class VI rule that seeks to protect potable groundwater. Limiting downsides is warranted, but policies may have undesired consequences if their implementation does not allow for uncertainty about physical processes. Other work has suggested that current regulatory systems for geologic $\mathrm{CO}_{2}$ storage may impede its deployment (Dammel et al., 2011). Here we show that variation and uncertainty in physical processes would lead to enormously different outcomes of leaked fluids reaching a USDW. The current framework of the U.S. EPA Class VI rule that addresses the potential contamination of groundwater would see all of these scenarios as identical despite the fact that some of these leakage outcomes may be inconsequential from the standpoint of physical processes and impacts. Such policies are not consistent with the goal of the federal government to enable CCUS as a strategy for climate mitigation.

These findings reveal a tension between the U.S. DOE storage permanence goal and the U.S. EPA Class VI rule. Because the simulations indicate that some of the $\mathrm{CO}_{2}$ that leaks will get to the USDW in the first year, an operation that meets the storage permanence goal could still be in violation of the Class VI rules if that leakage is detected in the USDW. One solution could be to forbid site development in areas where leakage would reach a USDW. Another solution could be to harmonize the U.S. EPA rule and U.S. DOE goal by assuring that wells that could leak into the USDW are leak tight to the extent possible, but that wells extending deeper and into the storage reservoir may be leaky to allow for the beneficial physical effects of leakage as we have shown. Such a tailored site development would leave the decisions up to the operator to determine the most cost-effective way to assess and remediate leaky wells because the specifics of the site will likely dictate if site development and operation is less expensive to seal fewer deep wells (and not have the benefits of leakage) than to seal numerous shallow wells (and have the benefits of leakage). Coordinating policies to be self-consistent and consistent with the 
physical processes they govern would enable balancing advancement of geologic $\mathrm{CO}_{2}$ storage and the climate mitigation it can achieve.

\section{Acknowledgements}

We thank David Bael, Joseph Dammel, Joshua Donato, Nathan Paine, and Mina Rahimi for their research assistance, Melisa Pollak for helping with data collection and analysis for the 3D model, and Thomas Elliot and Bin Guo for getting ELSA modeling initiated. We also thank the anonymous reviewers whose comments and insights helped us to improve the paper. This research was funded by the Department of Energy, Office of Fossil Energy, under Grant DE-FE0000749, and by the National Science Foundation under Sustainable Energy Pathways Grant (1230691) and under Grant CMMI-0919140. J. M. B. developed the methodology, acquired data, conducted analyses, analyzed results, and wrote the paper. E. J. W. wrote the paper. J. P. F. wrote the paper. C. A. P. analyzed results and wrote the paper. Disclaimer: Neither the U.S. government nor any agency thereof, nor any of their employees, makes any warranty, express or implied, or assumes any legal liability or responsibility for the accuracy, completeness or usefulness of any information, apparatus, product, or process disclosed, or represents that its use would not infringe privately owned rights. Reference herein to any specific commercial product, process, or service by trade name, trademark, manufacturer, or otherwise does not necessarily constitute or imply its endorsement, recommendation or favouring by the U.S. governing or any agency thereof. The views and opinions of authors expressed herein do not necessarily state or reflect those of the U.S. government or any agency thereof.

\section{References}

Atchley, A.L., Maxwell, R.M., Navarre-Sitchler, A.K., 2013. Human health risk assessment of CO2 leakage into overlying aquifers using a stochastic, geochemical reactive transport approach. Environ. Sci. Technol. 47, 5954-5962. doi:10.1021/es400316c

Bielicki, J.M., Pollak, M.F., Fitts, J.P., Peters, C.A., Wilson, E.J., 2014. Causes and financial consequences of geologic $\mathrm{CO} 2$ storage reservoir leakage and interference with other subsurface resources. Int. J. Greenh. Gas Control 20, 272-284. doi:10.1016/j.ijggc.2013.10.024

Birkholzer, J.T., Cihan, A., Bandilla, K., 2014. Perspective A tiered area-of-review framework for geologic carbon sequestration. Greenh. Gases Sci. Technol. 4, 20-35. doi:10.1002/ghg.1393

Birkholzer, J.T., Cihan, A., Zhou, Q., 2012. Impact-driven pressure management via targeted brine extraction-Conceptual studies of CO2 storage in saline formations. Int. J. Greenh. Gas Control 7, 168180. doi:10.1016/j.ijggc.2012.01.001

Birkholzer, J.T., Nicot, J.P., Oldenburg, C.M., Zhou, Q., Kraemer, S., Bandilla, K., 2011. Brine flow up a well caused by pressure perturbation from geologic carbon sequestration: Static and dynamic evaluations. Int. J. Greenh. Gas Control 5, 850-861. doi:10.1016/j.ijggc.2011.01.003

Birkholzer, J.T., Zhou, Q., 2009. Basin-scale hydrogeologic impacts of CO2 storage: Capacity and regulatory implications. Int. J. Greenh. Gas Control 3, 745-756. doi:10.1016/j.ijggc.2009.07.002

Birkholzer, J.T., Zhou, Q., Tsang, C.-F., 2009. Large-scale impact of CO2 storage in deep saline aquifers: A sensitivity study on pressure response in stratified systems. Int. J. Greenh. Gas Control 3, 181-194. doi:10.1016/j.ijggc.2008.08.002 
Buscheck, T.A., Elliot, T.R., Celia, M.A., Chen, M., Sun, Y., Hao, Y., Lu, C., Wolery, T.J., Aines, R.D., 2013. Integrated, geothermal-CO2 storage reservoirs: adaptable, multi-stage, sustainable, energy-recovery strategies that reduce carbon intensity and environmental. Energy Procedia 37, 6587-6594.

doi:http://dx.doi.org/10.1016/j.egypro.2013.06.591

Buscheck, T.A., Sun, Y., Chen, M., Hao, Y., Wolery, T.J., Bourcier, W.L., Court, B., Celia, M.A., Julio Friedmann, S., Aines, R.D., 2012. Active CO2 reservoir management for carbon storage: Analysis of operational strategies to relieve pressure buildup and improve injectivity. Int. J. Greenh. Gas Control 6, 230-245. doi:10.1016/j.ijggc.2011.11.007

Carey, J.W., 2013. Geochemistry of Wellbore Integrity in CO2 Sequestration: Portland Cement-SteelBrine-CO2 Interactions. Rev. Mineral. Geochemistry 77, 505-539. doi:10.2138/rmg.2013.77.15

Carey, J.W., Svec, R., Grigg, R., Zhang, J., Crow, W., 2010. Experimental investigation of wellbore integrity and CO2-brine flow along the casing-cement microannulus. Int. J. Greenh. Gas Control 4, 272 282. doi:10.1016/j.ijggc.2009.09.018

Catacosinos, P.A., Daniels Jr., P.A., Harrison III, W.B., 1990. Structure, Stratigraphy, and Petroleum Geology of the Michigan Basin, in: Selected Analog Interior Cratonic Basins (Vol. II). AAPG Special Volumes, pp. 561-601.

Catacosinos, P.A., Harrison III, W.B., Reynolds, R.F., Westjohn, D.B., Wollensak, M.S., 2000. Stratigraphic Nomenclature for Michigan. doi:10.1007/SpringerReference_30804

Celia, M. a., Nordbotten, J.M., Court, B., Dobossy, M., Bachu, S., 2011. Field-scale application of a semi-analytical model for estimation of $\mathrm{CO} 2$ and brine leakage along old wells. Int. J. Greenh. Gas Control 5, 257-269. doi:10.1016/j.ijggc.2010.10.005

Checkai, D., Bryant, S., Tao, Q., 2013. Towards a Frequency Distribution of Effective Permeabilities of Leaky Wellbores. Energy Procedia 37, 5653-5660. doi:10.1016/j.egypro.2013.06.487

Cihan, A., Birkholzer, J.T., Zhou, Q., 2013. Pressure buildup and brine migration during CO2 storage in multilayered aquifers. Groundwater 51, 252-67. doi:10.1111/j.1745-6584.2012.00972.x

Dammel, J. a, Bielicki, J.M., Pollak, M.F., Wilson, E.J., 2011. A tale of two technologies: hydraulic fracturing and geologic carbon sequestration. Environ. Sci. Technol. 45, 5075-6. doi:10.1021/es201403c

De Marsily, G., Delay, F., Goncalves, J., Renard, P., Teles, V., Violette, S., 2005. Dealing with spatial heterogeneity. Hydrogeol. J. 13, 161-183. doi:10.1007/s10040-004-0432-3

Deng, H., Ellis, B.R., Peters, C.A., Fitts, J.P., Crandall, D., Bromhal, G.S., 2013. Modifications of Carbonate Fracture Hydrodynamic Properties by CO2-Acidified Brine Flow. Energy \& Fuels 27, 42214231. doi:dx.doi.org/10.1021/ef302041s

Dobossy, M.E., Celia, M. a., Nordbotten, J.M., 2011. An efficient software framework for performing industrial risk assessment of leakage for geological storage of CO2. Energy Procedia 4, 4207-4214. doi:10.1016/j.egypro.2011.02.368

Duguid, A., Butsch, R., Carey, J.W., Celia, M., Chugunov, N., Gasda, S., Ramakrishnan, T.S., Stamp, V., Wang, J., 2013. Pre-injection Baseline Data Collection to Establish Existing Wellbore Leakage Properties. Energy Procedia 37, 5661-5672. doi:10.1016/j.egypro.2013.06.488 
Ellis, B.R., Fitts, J.P., Bromhal, G.S., McIntyre, D.L., Tappero, R., Peters, C.A., 2013. Dissolution-Driven Permeability Reduction of a Fractured Carbonate Caprock. Environ. Eng. Sci. 30, 187-193.

doi:10.1089/ees.2012.0337

Ellis, B.R., Peters, C.A., Fitts, J.P., Bromhal, G.S., Mcintyre, D., Warzinski, R., Rosenbaum, E., 2011. Deterioration of a fractured carbonate caprock exposed to CO2-acidified brine flow. Greenh. Gases Sci. Technol. 1, 248-260. doi:10.1002/ghg

European Union, 2009. Directive 2009/31/EC of the European Parliament and of the Council on the Geologial Storage of Carbon Dioxide. European Union.

Fitts, J.P., Peters, C.A., 2013. Caprock Fracture Dissolution and CO2 Leakage. Rev. Mineral. Geochemistry 77, 459-479. doi:10.2138/rmg.2013.77.13

GEA, 2012. Global Energy Assessment - Toward a Sustainable Future. Cambridge University Press, Cambridge UK.

Ha-Duong, M., Keith, D., 2003. Carbon storage: the economic efficiency of storing CO2 in leaky reservoirs. Clean Technol. Environ. Policy 5, 181-189. doi:http://dx.doi.org/10.1007/s10098-003-0213-z

Hepple, R.P., Benson, S.M., 2004. Geologic storage of carbon dioxide as a climate change mitigation strategy: performance requirements and the implications of surface seepage. Environ. Geol. 47, 576-585. doi:10.1007/s00254-004-1181-2

Hosseini, S.A., Nicot, J.-P., 2012. Scoping analysis of brine extraction / re-injection for enhanced CO 2. Greenh. Gases Sci. Technol. 2, 172-184. doi:10.1002/ghg.1283

Hovorka, S.D., Benson, S.M., Doughty, C., Freifeld, B.M., Sakurai, S., Daley, T.M., Kharaka, Y.K., Holtz, M.H., Trautz, R.C., Nance, H.S., Myer, L.R., Knauss, K.G., 2006. Measuring permanence of CO2 storage in saline formations: the Frio experiment. Environ. Geosci. 13, 105-121.

doi:10.1306/eg.11210505011

Humez, P., Audigane, P., Lions, J., Chiaberge, C., Bellenfant, G., 2011. Modeling of CO2 Leakage up Through an Abandoned Well from Deep Saline Aquifer to Shallow Fresh Groundwaters. Transp. Porous Media 90, 153-181. doi:10.1007/s11242-011-9801-2

IPCC, 2005. IPCC Special Report on Carbon Dioxide Capture and Storage, Prepared b. ed. Cambridge University Press, Cambridge UK.

Jordan, P.D., Oldenburg, C.M., Nicot, J.-P., 2011. Estimating the probability of CO 2 plumes encountering faults. Greenh. Gases Sci. Technol. 1, 160-174. doi:10.1002/ghg

Keating, E.H., Fessenden, J., Kanjorski, N., Koning, D.J., Pawar, R., 2010. The impact of CO2 on shallow groundwater chemistry: observations at a natural analog site and implications for carbon sequestration. Environ. Earth Sci. 60, 521-536. doi:10.1007/s12665-009-0192-4

Keating, E.H., Newell, D.L., Viswanathan, H., Carey, J.W., Zyvoloski, G., Pawar, R., 2013. CO2/Brine transport into shallow aquifers along fault zones. Environ. Sci. Technol. 47, 290-7.

doi:10.1021/es301495x 
Kestin, J., Shankland, I.R., 1984. Viscosity of Aqueous NaCI Solutions in the Temperature Range 25$200 \mathrm{oC}$ and in the Pressure Range 0.1-30 MPa. Int. J. Thermophys. 5, 241-263.

Kutchko, B.G., Strazisar, B.R., Dzombak, D.A., Lowry, G. V, Thaulow, N., 2007. Degradation of well cement by $\mathrm{CO} 2$ under geologic sequestration conditions. Environ. Sci. Technol. 41, 4787-4792.

Lampe, D.C., 2009. Hydrogeologic Framework of Bedrock Units and Initial Salinity Distribution for a Simulation of Groundwater Flow for the Lake Michigan Basin. Scientific Investigations Report 20095060 .

Lemieux, J.-M., 2011. Review: The potential impact of underground geological storage of carbon dioxide in deep saline aquifers on shallow groundwater resources. Hydrogeol. J. 19, 757-778.

doi:10.1007/s10040-011-0715-4

Lewicki, J.L., Birkholzer, J., Tsang, C.-F., 2006. Natural and industrial analogues for leakage of CO2 from storage reservoirs: identification of features, events, and processes and lessons learned. Environ. Geol. 52, 457-467. doi:10.1007/s00254-006-0479-7

Lions, J., Devau, N., de Lary, L., Dupraz, S., Parmentier, M., Gombert, P., Dictor, M.-C., 2014. Potential impacts of leakage from $\mathrm{CO} 2$ geological storage on geochemical processes controlling fresh groundwater quality: A review. Int. J. Greenh. Gas Control 22, 165-175. doi:10.1016/j.ijggc.2013.12.019

Little, M.G., Jackson, R.B., 2010. Potential impacts of leakage from deep CO2 geosequestration on overlying freshwater aquifers. Environ. Sci. Technol. 44, 9225-9232. doi:10.1021/es102235w

Matter, J.M., Takahashi, T., Goldberg, D., 2007. Experimental Evaluation of in situ CO2 -Water-Rock Reactions During CO2 Injection in Basaltic Rocks: Implications for Geological CO2 Sequestration. Geochemistry, Geophys. Geosystems 8, n/a-n/a. doi:10.1029/2006GC001427

Mazzotti, M., Pini, R., Storti, G., 2009. Enhanced coalbed methane recovery. J. Supercrit. Fluids. doi:10.1016/j.supflu.2008.08.013

NETL, 2010. Storing CO2 and Producing Domestic Crude Oil with Next Generation CO2-EOR Technology: An Update. DOE/NETL-2010/1417.

NETL, 2012. The United States 2012 Carbon Utilization and Storage Atlas.

Newell, D.L., Carey, J.W., 2013. Experimental evaluation of wellbore integrity along the cement-rock boundary. Environ. Sci. Technol. 47, 276-82. doi:10.1021/es3011404

NGDS, 2014. National Geothermal Data System [WWW Document]. U.S. Dep. Energy Geotherm. Technol. Progr. URL http://geothermaldata.org/

Nogues, J.P., Court, B., Dobossy, M., Nordbotten, J.M., Celia, M.A., 2012. A methodology to estimate maximum probable leakage along old wells in a geological sequestration operation. Int. J. Greenh. Gas Control 7, 39-47. doi:10.1016/j.ijggc.2011.12.003

Nordbotten, J.M., Kavetski, D., Celia, M., Bachu, S., 2009. Model for CO2 leakage including multiple geological layers and multiple leaky wells. Environ. Sci. Technol. 43, 743-749. 
Ogretim, E.O., Gray, D.D., Bromhal, G.S., 2014. Computational Study of Surface Signature of Anthropogenic CO2 at a Potential Carbon Sequestration Site, San Juan Basin. Environ. Eng. Sci. 31, 225 231. doi:10.1089/ees.2013.0386

Pacala, S., Socolow, R., 2004. Stabilization Wedges: Solving the Climate Problem for the Next 50 Years with Current Technologies. Science 305, 968-72. doi:10.1126/science.1100103

Pollak, M.F., Bielicki, J.M., Dammel, J. a., Wilson, E.J., Fitts, J.P., Peters, C. a., 2013. The Leakage Impact Valuation (LIV) Method for Leakage from Geologic CO2 Storage Reservoirs. Energy Procedia 37, 2819-2827. doi:10.1016/j.egypro.2013.06.167

Randolph, J.B., Saar, M.O., 2011. Combining geothermal energy capture with geologic carbon dioxide sequestration. Geophys. Res. Lett. 38, 1-7. doi:10.1029/2011GL047265

Randolph, J.B., Saar, M.O., Bielicki, J.M., 2013. Geothermal Energy Production at Geologic CO2 Sequestration sites: Impact of Thermal Drawdown on Reservoir Pressure. Energy Procedia 37, 66256635. doi:10.1016/j.egypro.2013.06.595

Rowe, A.M., Chou, J.C.S., 1970. Pressure-Volume-Temperature-Concentration Relation of Aqueous $\mathrm{NaCl}$ Solutions. J. Chem. Eng. Data 15, 61-66.

Rutqvist, J., 2012. The Geomechanics of CO2 Storage in Deep Sedimentary Formations. Geotech. Geol. Eng. 30, 525-551. doi:10.1007/s10706-011-9491-0

SMU, 2015. SMU Node of the National Geothermal Data System [WWW Document]. URL http://geothermal.smu.edu/gtda/

Span, R., Wagner, W., 1996. A New Equation of State for Carbon Dioxide Covering the Fluid Region from the Triple-Point Temperature to $1100 \mathrm{~K}$ at Pressures up to $800 \mathrm{MPa}$. J. Phys. Chem. Ref. Data 25, 1509-1596.

Stauffer, P.H., Viswanathan, H.S., Guthrie, G.D., 2009. A System Model for Geologic Sequestration of Carbon Dioxide. Environ. Sci. Technol. 43, 565-570. doi:10.1021/es800403w CCC:

Strandli, C.W., Benson, S.M., 2013. Identifying diagnostics for reservoir structure and CO 2 plume migration from multilevel pressure measurements. Water Resour. Res. 49, 3462-3475. doi:10.1002/wrcr.20285

Sun, A.Y., Zeidouni, M., Nicot, J.-P., Lu, Z., Zhang, D., 2013. Assessing leakage detectability at geologic $\mathrm{CO} 2$ sequestration sites using the probabilistic collocation method. Adv. Water Resour. 56, 49-60. doi:10.1016/j.advwatres.2012.11.017

Tao, Q., Bryant, S., Meckel, T., Luo, Z., 2012. Wellbore leakage model for above-zone monitoring at Cranfield, in: Carbon Management Technology Conference. Orlando, FL. doi:http://dx.doi.org/10.7122/151516-MS

U.S. EPA, 2012. The Electricity Generation \& Resource Integration Database.

U.S. EPA, 2013. Geologic Sequestration of Carbon Dioxide Underground Injection Control ( UIC ) Program Class VI Well Area of Review Evaluation and Corrective Action Guidance. EPA 816-R-13-005. 
U.S. Federal Register, 2010. Federal Requirements Under the Underground Injection Control (UIC) Program for Carbon Dioxide (CO2) Geologic Sequestratio (GS) Wells; Final Rule. United States of America.

Van der Zwaan, B., Gerlagh, R., 2009. Economics of geological CO2 storage and leakage. Clim. Change 93, 285-309. doi:10.1007/s10584-009-9558-6

Van der Zwaan, B., Smekens, K., 2009. CO2 Capture and Storage with Leakage in an Energy-Climate Model. Environ. Model. Assess. 14, 135-148. doi:10.1007/s10666-007-9125-3

Wainwright, H.M., Finsterle, S., Zhou, Q., Birkholzer, J.T., 2013 . Modeling the performance of largescale $\mathrm{CO} 2$ storage systems: A comparison of different sensitivity analysis methods. Int. J. Greenh. Gas Control 17, 189-205. doi:10.1016/j.ijggc.2013.05.007

Watson, T.L., Bachu, S., 2007. Evaluation of the Potential for Gas and CO2 Leakage along Wellbores, in: Society of Petroelum Engineers E\&P Environmental and Safety Conference. Galveston, TX, p. 16.

Watson, T.L., Bachu, S., 2008. Identification of Wells with High CO 2 -Leakage Potential in Mature Oil Fields Developed for CO2 -Enhanced Oil Recovery, in: 2008 SPE Improved Oil Recovery Symposium. SPE 112924, p. 10.

Yang, C., Dai, Z., Romanak, K.D., Hovorka, S.D., Trevino, R., 2014a. Inverse Modeling of Water-Rock$\mathrm{CO}_{2}$ Batch Experiments: Potential Impacts on Groundwater Resources at Carbon Sequestration Sites. Environ. Sci. Technol. 48, 2789-2806. doi:dx.doi.org/10.1021/es4041368

Yang, C., Hovorka, S.D., Young, M.H., Trevino, R., 2014 b. Geochemical Sensitivity to $\mathrm{CO}_{2}$ Leakage: Detection in Potable Aquifers at Carbon Sequestration Sites. Greenh. Gases Sci. Technol. 4, 384-399. doi:10.1002/ghg. 1406

Zeidouni, M., 2012. Analytical model of leakage through fault to overlying formations. Water Resour. Res. 48, 1-17. doi:10.1029/2012WR012582

Figures And Tables:

Figure 1: $\mathrm{CO}_{2}$ injection case study in the Michigan sedimentary basin - The wells terminating in the deepest nine hydrostratigraphic units are colored by the units in which they terminate.

Figure 2: Modeled aquifer sequence and properties near injection site at James De Young power plant, Ottawa County, Michigan (U.S.A.). The shallowest aquifer in the modeled sequence represents the underground source of drinking water (USDW).

Figure 3 provides an overview of the simulation methodology described above.

Figure 4: Overview of the methodology for probabilistic simulation of leakage from geologic $\mathrm{CO}_{2}$ storage reservoirs. 
Figure 5: Simulation results showing the profiles of the $\mathrm{CO}_{2}$ plumes and brine pressure increases in the Mt. Simon storage reservoir and the overlying Galesville formation after 30 years of 20 $\mathrm{MtCO}_{2} / \mathrm{yr}$ injection.

Figure 7: Annual $\mathrm{CO}_{2}$ accumulation in geologic sequence averaged over 30 years of continuous injection and leakage.

Figure 9: Cumulative distributions of the simulation results of leaked $\mathrm{CO}_{2}$ accumulating in the overlying (Galesville) and USDW (Quaternary to Marshall) aquifers after 30 years of continuous injection and leakage when all wells are leakage pathways

Figure 11: Percentage of cumulative $\mathrm{CO}_{2}$ having leaked from the Mt. Simon over time when all wells leak. The markers indicate the injection rate: diamonds are $4 \mathrm{MtCO} / \mathrm{yr}$ injections, triangles are $12 \mathrm{MtCO} / \mathrm{yr}$ injections, and circles are $20 \mathrm{MtCO}_{2} / \mathrm{yr}$ injections. The hollow markers show the average of the 100 simulations for $\kappa_{\text {leak }}=10^{-10} \mathrm{~m}^{2}$ (in red) and for $\kappa_{\text {leak }}=$ $10^{-12} \mathrm{~m}^{2}$ (in green). The solid markers show the average of the 400 simulations for each injection rate.

Figure 12: Extents of the $\mathrm{CO}_{2}$ plumes (a) map view of probabilities of $\mathrm{CO}_{2}$ being present, by quartile, for the 400 simulations of $20 \mathrm{MtCO}_{2} / \mathrm{yr}$ injection for 30 years when all wells leak, and (b) probabilities of $\mathrm{CO}_{2}$ being present east of the injection location by injection rate and leakage condition. Injection rates are indicated by different markers: $20 \mathrm{MtCO}_{2} / \mathrm{yr}$ (circles), 12 $\mathrm{MtCO}_{2} / \mathrm{yr}$ (triangles), $4 \mathrm{MtCO}_{2} / \mathrm{yr}$ (diamonds). Leakage conditions are indicated by line types: no leakage (solid lines), one well leaks (dashed lines), all wells leak (dotted line). The map view in (a) corresponds to the solid line with circle markers in (b).

Figure 14: Expectation of the reduction in the Area of Review (AoR) over time, when all wells leak. The height of the bars (left) indicates the portion of the locations where the probability of $\mathrm{CO}_{2}$ being present is reduced due to leakage. Leakage will be expected to reduce the AoR if the height of a bar is greater than $50 \%$ (indicated by the red line). The thick black lines (right) indicate the average difference of these probabilities over all spatial locations, and the ranges on the line markers indicate the standard deviation of these differences.

Table 1: Simulation results and select natural analogs of $\mathrm{CO}_{2}$ leakage (Lewicki et al., 2006).

Location

(e) Solfatara (IT)

(d) Mammoth Mountain

(USA)

(c) Albani Hill (IT)

(b) Crystal Geyser (USA)

(a) Laacher See (DE)
$\mathrm{CO}_{2}$ Accumulation $\left(\mathrm{tCO}_{2} / \mathrm{y}\right)$

Surface Groundwater Percentage of Laacher See

$547,500 \quad 3,746,716^{* *}$

$91,250 \quad 623,953 * *$

$27,010 \quad 184,690$

$12,045 \quad 82,362 * *$

$5,110 \quad 34,941 * *$ 


\section{James De Young}

$4 \mathrm{MtCO}_{2} / \mathrm{yr}$

$72 * *$

$82 * *$

$489 *$

$1.4 \%$

$12 \mathrm{MtCO}_{2} / \mathrm{yr}$

$85^{* *}$

$558 *$

$1.6 \%$

$20 \mathrm{MtCO}_{2} / \mathrm{yr}$

$581 *$

$1.7 \%$

*Simulated Data; **Extrapolated based on Albani Hill (IT) ratio 